\title{
TERMO DE CONCILIAÇÃO NAS COMISSÕES DE CONCILIAÇÃO PRÉVIA: NATUREZA JURÍDICA E EFICÁCIA LIBERATÓRIA
}

\author{
Guilherme Guimarães Feliciano \\ Juiz Federal do Trabalho, Professor da Faculdade de Direito \\ da Universidade de Taubaté e Doutorando da Faculdade de \\ Direito da Universidade de São Paulo
}

\begin{abstract}
Resumo:
O fenômeno da litigiosidade estimulada, que no País passou a ser visto pelo jurista como perspectiva de ganho fácil e imediato; trabalhadores que em desamparo têm como derradeiro fôlego de subsistência o acesso à Instância do Trabalho, empresa às voltas com o fantasma da falência, são alguns dos itens abordados pelo autor neste trabalho.

Abstract:

The phenomenon of stimulated litgationess, that in the Country has been seen by the jurists as a perspective of immediate and easy profits; unhelped workers that have as last subsistence's breath the access to the Labor Jurisdiction, enterprise surrounded with the phantom of the bankruptcy, are some of the itens boarded by the author in this article.
\end{abstract}

Unitermos: Comissão de Conciliação Prévia; eficácia liberatória; natureza jurídical.

A Lei n. 9.958, de 12.01.2000, integrou-se ao ordenamento jurídico brasileiro com o propósito declarado de estancar a sangria de dissídios individuais que assoberbam a Justiça do Trabalho de primeira instância. Acenou aos operadores do Direito do Trabalho no sentido de reconhecer, na seara trabalhista, fenômeno inverso à litigiosidade contida, fenômeno sociológico apontado por Kazuo Watanabe e outros' como justificação política para os juizados especiais das causas cíveis de menor

I. Kazuo Watanabe et al., Juizado Especial de Pequenas Causas, São Paulo, RT, 1985, passim. Confirase ainda, para a correlação do teına com a questão do acesso à Justiça, "Por uma Justiça Eficiente" de José Renato Nalini, in http://neofito.direito.com.br/artigos/art0l/jurid 135.htm (29.10.0I - site “O Neófito"): "Muito poderia ser feito pelos poderes locais para aperfeiçoar a própria Justiça. O gigantismo de São Paulo permitiria a adoção de alternativas eficazes à simplificação do Judiciário. Sem excluir outras propostas, seria conveniente meditar sobre: (...) exercício das competências constitucionais, notadamente quanto a legislar sobre criação, funcionamento e processo do Juizado de Pequenas Causas e sobre procedimentos em matéria processual. As causas pequenas nāo são as menos sérias. Adequadamente resolvidas, atenuarão a litigiosidade contida e a crítica procedente quanto à ineliciência da Justiçai. O Judiciário tem também o dever de se autoprover de instrumentos aptos à conversão de seus préstimos eım efetivo serviço e o principal deles é o processo" (g.n.). 
complexidade: no mundo do trabalho, ao revés, dá-se, no Brasil, o fenômeno da litigiosidade estimulada, de tal maneira que o acesso à Justiça do Trabalho, sobre ser facilitado, passou a desafiar óticas mais prosaicas: passou a ser visto, por alguns advogados, como perspectiva de ganho fácil e imediato; por alguns trabalhadores, já ao desamparo, como um derradeiro fôlego de subsistência (quiçá um sucedâneo do seguro-desemprego, que deveria, em tese, assisti-lo durante todo o período de inatividade econômica, e raramente o faz); por algumas empresas, às voltas com o fantasma da falência, como garantia de quitação geral de créditos trabalhistas obtida a preços módicos. Justamente para conter essa assombrosa indústria de litígios, redirecionandoos para outro pólo institucional, o legislador pátrio trouxe à luz as comissões de conciliação prévia, agregando à Consolidação das Leis do Trabalho os art. 625-A a 625-H.

Na prática forense, porém, a sua aplicação tem suscitado celeumas contumazes quanto à natureza jurídica da tentativa prévia de conciliação e quanto à extensão da eficácia liberatória geral predisposta pelo parágrafo único do art. 625-E da CLT.

Quanto ao primeiro aspecto, impende notar, desde logo, que o caput do art. 625-C da CLT, ao estatuir que "qualquer demanda de natureza trabalhista será submetida à Comissão de Conciliação Prévia se, na localidade da prestação de serviços, houver sido instituída a Comissão no âmbito da empresa ou do sindicato da categoria" não criou uma nova condição, de natureza eventual, para o exercício do direito de ação na Justiça do Trabalho; tampouco pode ser reputado manifestação concreta de uma das clássicas condições da ação, a saber, a legitimidade ad causam, o interesse de agir e a possibilidade jurídica. Como assertado por Estêvão Mallet, "não está em lugar algum da Lei n. 9.958/00 a afirmação de que a falta de tentativa prévia de conciliação torna o reclamante carecedor de ação. (...) De outro lado, a carência de ação, por falta de tentativa de conciliação, não pode ser simplesmente deduzida do conceito de interesse processual" vez que "mesmo não tentada a conciliação prévia, havendo defesa na reclamação ou não pagamento dos valores cobrados, surge o interesse processual, diante da resistência do reclamado. Torna-se, em conseqüência, irrelevante a carência inicial da ação. (...) Ademais, não se deve perder de vista que na reclamação será, antes mesmo de que se defenda o reclamado, obrigatoriamente tentada a conciliação" de forma que "não faria sentido extinguir o processo por ausência de tentativa de conciliação" 2

É certo, todavia - e nesse ponto discordo do escólio invocado -, que o preceito em comento criou, sob certas circunstâncias (a instituição, na localidade da prestação dos serviços do autor, de comissão de conciliação prévia no âmbito da empresa ou do sindicato da categoria profissional pertinente), um óbice processual ao desenvolvimento válido do processo. Daí a compreensão de que o caput do artigo 625 -

2. Estêvão Mallet, "Primeiras Linhas sobre as Comissōes de Conciliação", in Revista LTr 64-()4/ 444-445. 
D da CLT introduziu, para as ações reclamatórias trabalhistas, um pressuposto processual específico, qual seja, a sujeição da demanda de natureza trabalhista o que afasta a possibilidade de que as comissões homologuem acordos sem o reconhecimento de vínculo empregatício - à comissão de conciliação prévia instituída na localidade de prestação de serviços (= jurisdição territorial da Vara do Trabalho), no âmbito da empresa ou do sindicato, ao qual está vinculado o trabalhador.

É, aliás, pressuposto processual similar àquele ditado pela Constituição Federal de 1988 para os litígios de natureza tipicamente desportiva ("O Poder Judiciário só admitirá ações relativas à disciplina e às competições desportivas após esgotaremse as instâncias da justiça desportiva, reguladas em lei" art. 217, \$1") ou para os próprios dissídios coletivos de natureza econômica. ("Recusando-se qualquer das partes à negociação ou à arbitragem, é facultado aos respectivos sindicatos ajuizar dissídio coletivo (...)" - art. 114, \$2"). Ali, exige-se o esgotamento da via administrativa a justiça desportiva - para que o processo judicial desenvolva-se validamente; aqui, exige-se - nos dissídios coletivos e, agora, em parte dos dissídios individuais - a tentativa prévia de negociação (que se dá, nesse último caso, perante as comissões prévias de conciliação). Desse modo, a ausência daquele pressuposto processual, por inexistente a sujeição prévia à comissão instituída na localidade, impede o desenvolvimento válido do processo trabalhista e, por conseguinte, preordena a respectiva extinção scm julgamento de mérito, com espeque no art. 267, IV, do Código de Processo Civil. Pressupostos processucais são, com efeito, "os requisitos necessários à formação e desenvolvimento da relação processual"; do ponto de vista subjetivo, "os pressupostos intrínsecos à relação processual concernem à regularidade dos atos nela praticados, que deverão ser acordes com as disposições legais que os regulam. Se, por acaso, as infringirem, serão alvo de invalidação, podendo comprometer o próprio processo, quando a gravidade da infração ultrapassar os limites tolerados pela lei" A A infração, na espécie, dá-se pela omissão do autor, que deveria primeiramente submeter o litígio de natureza trabalhista à comissão de conciliação prévia.

O segundo aspecto diz com o parágrafo único do art. 625-E da CLT, pelo qual "o termo de conciliação é título extrajudicial e terá eficácia liberatória geral, exceto quanto às parcelas expressamente ressalvadas" A eficácia liberatória geral, nos termos de conciliação idôneos, há de ter o alcance exato de sua expressão (interpretação declaratória ${ }^{5}$ ). Tal expressão, mais ampla que aquela empregada pelo

3. A doutrina tem reconhecido, porém, que a negociação coletiva é uma condição específica da ação coletiva trabalhista (dissídio coletivo de natureza econômica). Cfr. Arion Sayão Romita, Os Direitos Sociais na Constituição e Outros Estudos, São Paulo, LTr, 199I, p.353; Amauri Mascaro Nascimento, Curso de Direito Processual do Trabalho, I4a ed., S.Paulo, Saraiva, 1993, pp.398-399.

4. Egas Dirceu Moniz de Aragāo, Comentários ao Código de Processo Civil, v. II, 9a ed., Rio de Janeiro, Forense, 2000, pp.386-387.

5. Atitude hermenêutica oriunda do Direito Romano clássico, em que o jurista "verificava que o espírito da lei correspondia à letra, não havendo necessidade, portanto, de restringi-la ou ampliá-la" (José Carlos Moreira Alves, Direito Romano, v. I, 7a ed., Rio de Janeiro, Forense, 1991, p. 103). 
Enunciado n. 330 do C.TST na exegese do art. 477, \$1", da CLT ( "eficácia liberatória en relação às parcelas expressamente consignadas"), não pode ensejar interpretação de iguais dimensões, sob pena de tornar inútil a redação da lei; ainda que não seja feliz a opção legislativa, legem habenus. Nesse sentido: "O efeito liberatório alcança, ainda, as parcelas e direitos pleiteados mas não ressalvados de forma expressa e aqueles não reclamados pelo trabalhador perante a comissão (aponta neste sentido, a concessão de efeito liberatório geral ao termo de acordo"'. Ou ainda: "Quanto ao efeito liberatório do termo de conciliação firmado perante a Comissão Prévia, entendemos que impedirá que o empregado venha postular novamente junto à Justiça do Trabalho, salvo com relação às parcelas que forem objeto de ressalva expressa, hipótese em que o dissídio individual estará restrito àquela matéria delimitada"7 . A ressalva, legalmente prevista para mitigar a eficácia liberatória da transação perante as comissões, "identifica o termo de conciliação celebrado no âmbito da Comissão como as homologações de rescisões contratuais feitas pelos sindicatos brasileiros, as quais, salvo raríssimas (e cada vez mais raras) rescisões, a maioria (totalidade?) consigna, no verso, o tradicional carimbo ressalvando diferenças, a tal ponto que ensejou mudança da redação original

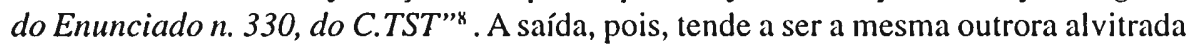
pelos sindicatos à luz da redação original do Enunciado n. 330: inclusão, nos termos de conciliação, de textos padronizados com ressalvas expressas e abrangentes.

Penso, por conseguinte, que, se a conciliação é aceita e as partes lavram com os conciliadores, o termo de conciliação descrito no art. 625-E, com "eficácia liberatória geral" a ação judicial tendente a reclamar títulos dimanados da relação extinta não há de ser conhecida, por ser o autor - agora sim - carente de ação, por falta de interesse de agir (art. 267, VI, do CPC): tendo transigido validamente, com os efeitos do art. 1.030 do Código Civil, e conferindo o título eficácia liberatória geral ao empregador, não há qualquer utilidade na ação judicial, seja porque o trabalhador já recebeu o que the é devido, seja porque não o recebeu e deve executar o termo de conciliação (art. 876, caput, da CLT), seja, enfim, porque concedeu quanto àquilo que entendia devido, era litigioso e não the foi pago (logo, não the é mais, sequer em tese, devido). Haverá, porém, interesse de agir, se a causa petendi fizer vislumbrar a utilidade do provimento jurisdicional pretendido; assim, por exemplo, se a petição inicial argúi, a propósito da transação e do ato jurídico que a consubstanciou, a inexistência (e.g., comissão constituída em desconformidade com os art. 625-A usque 625-H, em desacordo com a lei civil ou ainda contra as normas de funcionamento de acordo ou convenção coletiva - art. 625-C da CLT; termo não-assinado pelos membros da comissão

6. Cleber Lúcio de Alıneida, "Coınissões de Conciliação Prévia æ Considerações sobre a Lei n. 9.958/2000", in Revista LTr 64-02/227.

7. Narciso Figueirôa Júnior, "As recentes alterações na legislação trabalhista a Leis ns. 9.957 e 9.958 de 12 de janeiro de 2000", in Revista LTr 64-02/200.

8. Georgenor de Souza Franco Filho, "A Lei das Comissōes de Conciliação Prévia", in Revista LTr 64-02/175. 
etc.), a nulidade (absoluta - v.g., empregado incapaz de transigir por si mesmo, por ser alienado ou menor de dezoito anos ou relativa, dita também anulabilidade coação, dolo, erro substancial, falsa causa, títulos não-litigiosos ${ }^{9}$ etc.) ou ineficácia (v.g., pedido de restituição de coisa devida por direito real ou pessoal, porém arrecadada pela massa falida e alienada, como dação em pagamento, em acordo firmado com ex-empregado seu perante comissão de conciliação prévia art. 76, caput e \$ l", do Decreto-lei 11. 7.661/45; indicação à penhora de bem do empregador dado em pagamento a terceiro empregado, sob os auspícios de comissão de conciliação prévia, sem rateio e de molde a torná-la insolvente no processo).

Da mesma forma, é inadmissível o reconhecimento da eficácia liberatória geral contra direitos que, à época da transação extrajudicial, não pudessem razoavelmente integrar a esfera de cognição do hipossuficiente econômico. Assim, por exemplo, o direito à estabilidade convencional dimanado de doença do trabalho ou moléstia profissional (art. 20, I e II, da Lei n. 8.212/91) que, manifestadas após a extinção do contrato de trabalho, guarde etiologia com o labor envidado por conta do vínculo empregatício; da mesma forma, o dano moral provocado pelas injúrias disseminadas após a dispensa, de que o trabalhador veio a ter conhecimento somente após firmar o acordo, ou ainda os benefícios de expressão econômica de uma lei ulterior com efeitos retroativos. Em todos esses casos, o termo de conciliação, ainda que existente, válido e eficaz, não elide o direito de o empregado ajuizar ação reclamatória trabalhista para a tutela dos direitos de cognição tardia e de, adiante, vê-la apreciada em seu mérito.

$$
\text { É como entendo, s.m.j. }
$$

São Paulo, janeiro de 2002.

9. Assim, e.g., quando o empregador reconhece in totum os direitos rescisórios do empregado mas, ainda assim, leva-o perante comissão de conciliação prévia para ali barganhar redução percentual do total devido e incontroverso, além de parcelá-lo sem qualquer ônus para a empresa. Em casos dessa natureza, nāo se há de falar em transaçāo, ante o caráter não-litigioso dos títulos em jogo; houve, ao revés, renúncia parcial a que foi induzido o hipossuficiente, para cuja homologação não estão autorizadas, expressamente, as comissões de conciliação prévias. Com efeito, o vocábulo conciliação abrange, na melhor doutrina, a transação e o reconhecimento jurídico do pedido (cfr. Valentim Carrion, Comentários à Consolidação das Leis do Trabalho, 2 la edição, São Paulo, Saraiva, 1996 (agosto), p.613); jamais, porém, a renúncia. 